\title{
Análise da aplicação de uma escala de dependência do uso do telefone celular na pós-graduação durante a pandemia da Covid-19
}

Ricardo Barbosa Bitencourt, IFSertãoPE - Campus Petrolina / UNEB-PPGEcoH, ricardo.bitencourt@ifsertao-pe.edu.br, https://orcid.org/0000-0002-3438-6912

Ralliny Soares Rocha dos Santos, UNEB-PPGEcoH, ralliny@outlook.com, https://orcid.org/0000-0002-1171-3909

Dinani Gomes Amorim, FACAPE / UNEB-PPGEcoH, dinaniamorim@gmail.com, https://orcid.org/0000-0002-0399-3621

Ricardo José Rocha Amorim, FACAPE / UNEB-PPGEcoH, amorim.ricardo@gmail.com, https://orcid.org/0000-0001-9527-2751

Resumo. O controle da Covid-19 exigiu estratégias não farmacológicas importantes, a exemplo do uso de máscaras, isolamento e distanciamento social. A suspensão de diversas atividades presenciais, especialmente as escolares, obrigou a implantação do ensino remoto. Este, de fato, se constitui em um novo formato de relacionamento entre professores e alunos e que tem o smartphone como um importante aliado. Contudo, o uso mais acentuado desse dispositivo, sem qualquer planejamento anterior, vem contribuindo para uma exposição dos usuários a adoecimentos da era digital. Para ilustrar essa questão, avaliou-se a possível condição dessa relação por intermédio da aplicação de uma Escala de Dependência do Telefone Celular junto à uma comunidade acadêmica de pósgraduação no interior baiano (discentes, docentes e técnicos administrativos). Os resultados mostram que, apesar de não haver prevalência de gravidade, os participantes já apresentam algum tipo de dependência do uso do celular.

\section{Palavras-chave: Cultura digital; Saúde Mental; Nomofobia.}

\section{Analysis of the application of a scale of dependence on cell phone use in graduate courses during the Covid-19 pandemic}

\begin{abstract}
Controlling Covid-19 required important non-pharmacological strategies, such as the use of masks, isolation, and social distancing. The suspension of several on-site activities, especially school activities, forced the implementation of remote learning. This, in fact, constitutes a new relationship format between teachers and students, which has the smartphone as an important ally. However, the more accentuated use of this device, without any previous planning, has been contributing to an exposure of users to illnesses of the digital age. To illustrate this issue, the possible condition of this relationship was assessed through the application of a Cell Phone Dependence Scale (CPDS) with a graduate academic community in the interior of Bahia (students, teachers and administrative technicians). The results show that, although there is no prevalence of severity, the participants already have some type of dependence on cell phone use.
\end{abstract}

Keywords: Digital culture; Mental health; Nomophobia. 


\section{Introdução}

A pandemia causada pela Covid-19 transformou a realidade mundial. Com o isolamento e o distanciamento sociais sendo aplicados como recursos não farmacológicos essenciais para o controle da doença, o uso das Tecnologias da Informação e Comunicação (TICs) surgiu como estratégia viável para a manutenção de atividades que foram totalmente suspensas ou de forma parcial (FREITAS et al., 2021; PISSAIA et al., 2021; DE ARAÚJO et al., 2020; MÉLO, 2020).

Na educação, a Portaria Ministerial n. ${ }^{0} 544$ de 16 de junho de 2020 permitiu a substituição das aulas presenciais pelas mediadas por meios digitais, enquanto durasse a situação de pandemia do novo coronavírus. No ensino superior, isso também já havia sido regulamentado pela Portaria n. ${ }^{\circ} 343$ de 17 de março de 2020, que, entre outros pontos, passou a "autorizar, em caráter excepcional, a substituição das disciplinas presenciais em andamento, por aulas que utilizem meios e tecnologias de informação e comunicação" (BRASIL, 2020).

Esse movimento de adoção das TICs para a mediação do ensino recebeu diversos nomes, como ensino a distância, ensino online, ensino híbrido e atividade escolar remota (DE ARAÚJO et al., 2020, p. 865). Ele teve como grande entrave o acesso precário à internet e a equipamentos adequados, especialmente para os alunos do ensino público e de áreas não urbanas (FREITAS et al., 2021; MÉLO, 2020).

A busca por uma infraestrutura mínima para acompanhar essa mudança levou o Brasil a registrar mais de 234 milhões de acessos móveis (ANATEL, 2020), consolidando o smartphone como principal estratégia de manutenção de atividades do cotidiano que incluía, agora de forma regular, as rotinas escolares (DE ANDRADE CARNEIRO, 2020).

A mediação tecnológica de rotinas presenciais fez com que o brasileiro necessitasse usar o celular constantemente. Dados da pesquisa App Annie (2021) apontam que o brasileiro permaneceu 4,8 horas por dia com o celular em uso, uma hora a mais do que o registrado na mesma pesquisa no ano anterior.

Esse uso excessivo acende um alerta para possíveis danos à saúde, associados ao uso constante de tecnologia, como o vício vinculado ao uso do telefone. Esse fenômeno, nos últimos anos, vem suscitando a atenção de clínicos e pesquisadores do mundo todo, por seu uso ter sido relacionado a comportamentos prejudiciais à saúde individual e coletiva (DE ABREU, 2013, p. 104). "Essa interatividade prolongada diária está causando mudanças pessoais, comportamentais e sociais. Portanto, não devemos perder de vista os efeitos benéficos e prejudiciais desse relacionamento" (KING et al., 2019, p.1).

O uso abusivo de tecnologia ainda não possui uma classificação, como já é previsto para as desordens de jogo (CID 6C51), sendo nomofobia o termo mais utilizado para caracterizar essa relação de adoecimento. A "nomofobia ainda não foi inserida no Código Internacional de Doenças (CID-11) e no Manual Diagnóstico e Estatístico de Transtornos Mentais (DSM-5) como uma patologia relacionada ao vício" (MORILLA et al., 2020, p. 124), apesar de seus sintomas estarem dentro das fobias por coisas particulares e específicas. Ela se refere a uma condição psicológica em que as pessoas possuem uma fobia de serem desligadas da conectividade do telefone móvel, ficarem sem celular ou serem incapazes de utilizá-lo, devido à falta da internet ou bateria (BHATTACHARYA, 2019; PINHEIRO; PINHEIRO, 2021; MAZIERO; OLIVEIRA, 2016; BORGES; PIGNATARO, 2016; NÚÑEZ, 2020).

Segundo Oliveira (2013), é possível que mais de $10 \%$ da população brasileira, que têm o celular como maior instrumento de acesso, estejam desenvolvendo um quadro de dependência digital. O trabalho de Pinheiro e Pinheiro (2021) aponta que a dependência 
pode chegar a tal nível que o celular passa a ser parte externalizada do próprio corpo, servindo, inclusive, como memória auxiliar do indivíduo.

É importante salientar que o uso não saudável da tecnologia contribui para insegurança, baixa autoestima, fobia social, ansiedade e personalidade introvertida. Os sintomas mais observados dentro desse quadro são agitação, nervosismo, suor, tremores, angústia, taquicardia, entre outros, especialmente quando o indivíduo está por algum motivo impedido de usar o celular ou o computador (PINHEIRO; PINHEIRO, 2021; MAZIERO; OLIVEIRA, 2016).

Dado o contexto em tela, a realização de pesquisas sobre o tema é necessária para a observação do fenômeno no cenário brasileiro e em diferentes contextos. Dessa forma, o presente trabalho analisou o resultado da aplicação de uma escala de dependência de celular (KING, 2019) junto à membros da comunidade acadêmica de um curso de pósgraduação.

\section{Materiais e métodos}

Trata-se de uma pesquisa descritiva, em que se busca a identificação e descrição de características de grupos ou de fenômenos (GIL, 2002; SEVERINO, 2017), realizada no primeiro semestre de 2021, envolvendo professores, técnicos administrativos e alunos (com matrículas ativas em 2019 e 2020) de um programa de pós-graduação (mestrado e doutorado).

Não houve qualquer abordagem, presencial ou síncrona, em relação aos participantes. Toda a comunicação foi realizada por e-mail, a partir de uma lista de contatos solicitada à coordenação do programa. Alguns reforços ao convite foram encaminhados para grupos de WhatsApp nos quais o público-alvo interagia, mas sem qualquer abordagem pessoal ou personalizada.

Para evitar participantes de fora do contexto do público-alvo, os e-mails dos respondentes foram conferidos junto à lista de contatos anteriormente encaminhada pela coordenação. Por fim, de um total de 103 participantes qualificados a participar, 61 responderam ao teste, conforme descrito na Tabela 1.

Tabela 1 - Distribuição de participantes por tipo de relação com o Programa de Pós-graduação

\begin{tabular}{lcc}
\hline Categoria & $\begin{array}{c}\text { Participantes } \\
\text { Contactados }\end{array}$ & $\begin{array}{c}\text { Respondeu ao } \\
\text { questionário }\end{array}$ \\
\hline Docente & 25 & 11 \\
\hline Discente Mestrado & 35 & 21 \\
\hline Discente Doutorado & 34 & 26 \\
\hline Técnico Administrativo & 9 & 3 \\
\hline
\end{tabular}

Fonte: dados da pesquisa.

\subsection{Instrumentos}

Para a coleta das informações, utilizou-se a escala de dependência do telefone celular validada por King (2019) e colaboradores. Embora existam outros testes (CHÓLIZ, 2012; LIN, 2014; KWON et al., 2013), a escolha da escala se deu por sua validação recente em relação à realização da pesquisa (2019), assim como por envolver 
uma busca de relação de dependência com o telefone, independentemente do acesso à internet, e por ter sido desenvolvida e validada no contexto brasileiro.

A escala foi disponibilizada aos participantes através de um formulário do Google, esclarecendo que o resultado do teste não consistia em um laudo e nem pode ser utilizado como tal. Foi informado também que os dados coletados poderiam ser usados em publicações sobre a temática, e nenhum usuário teria acesso aos dados dos outros usuários. O instrumento foi submetido ao comitê de ética para uma pesquisa relacionada e autorizado através do parecer 4.150.399 de 13 de julho de 2020.

Esclareceu-se que a participação era voluntária, não obrigatória e sem qualquer tipo de remuneração. Ao final do preenchimento do formulário, o participante recebeu em seu e-mail uma cópia de suas respostas e um link para consultar o seu resultado.

O formulário era dividido em duas partes. Na primeira, foram coletadas informações relativas ao gênero, à idade, se trabalha e a condição de participação no Programa de Pós-graduação. Na segunda, o participante encontrava as 16 questões da escala de Dependência do Telefone Celular (DTC). Em cada pergunta, o partícipe possuiu três opções de resposta: 0 - Nunca / Raramente; 1 - Frequentemente; 2 - sempre. Ao final, a soma das respostas apontava para uma condição de dependência do celular, a seguir:

- Até 2 pontos (sem sinais de abuso e existência de total controle sobre o seu uso no dia a dia);

- 3 - 12 (Leve: sinais de uma possível dependência de telefones celulares);

- 13 - 22 (Moderado: você tem sinais de uma possível dependência do telefone celular);

- 23 - 32 (Grave: o uso do telefone celular está causando graves problemas em sua vida pessoal, social, familiar, acadêmica ou profissional).

\section{Resultados}

Do universo participante (61 pessoas), $56 \%$ foram do sexo feminino e $44 \%$ do sexo masculino. Em relação à idade, 3\% tinham entre 20 e 25 anos, $7 \%$ de 26 a 31 anos, $21 \%$ de 32 a 37 anos, $25 \%$ entre 38 e 43 anos, $21 \%$ de 44 a 49 anos e $23 \%$ de 50 anos ou mais.

Na Tabela 2, o resultado dos testes, dividido pelas questões, revela o cenário geral de condição dos participantes. Ele se concentra nos resultados que revelam o uso e a manutenção ativa do celular, em contraste com as respostas que possuem alguma relação com as respostas comportamentais, as associadas à ansiedade ou alguma forma de comportamento considerado negativo.

Tabela 2 - Respostas dadas ao Teste de Dependência do uso do Celular em que "0" corresponde a Nunca/raramente, " 1 " frequentemente e " 3 " sempre

\begin{tabular}{lccc}
\multicolumn{1}{c}{ Questões } & $\mathbf{0}$ & $\mathbf{1}$ & $\mathbf{2}$ \\
\hline $\begin{array}{l}\text { 1. Com que frequência você usa o Telefone Celular no seu dia a } \\
\text { dia? }\end{array}$ & $2 \%$ & $23 \%$ & $\mathbf{7 5 \%}$ \\
\hline $\begin{array}{l}\text { 2. Com que frequência você não consegue sair sem levar o } \\
\text { Telefone Celular? }\end{array}$ & $46 \%$ & $31 \%$ & $23 \%$ \\
\hline $\begin{array}{l}\text { 3. Com que frequência quando você esquece o Telefone Celular } \\
\text { costuma voltar para buscá-lo? }\end{array}$ & $36 \%$ & $\mathbf{3 4 \%}$ & $\mathbf{3 0 \%}$ \\
\hline $\begin{array}{l}\text { 4. Com que frequência você acessa a internet no Telefone Celular? } \\
\text { 4. 3\% }\end{array}$ & $30 \%$ & $\mathbf{6 7 \%}$ \\
\hline
\end{tabular}


$\begin{array}{lllll}\text { 5. Com que frequência você sente ansiedade quando percebe que } & \mathbf{5 6 \%} & 31 \% & 13 \%\end{array}$ está sem o Telefone Celular?

\begin{tabular}{lllll}
\hline 6. Com que frequência você se sente triste ou depressivo quando & $\mathbf{7 4 \%}$ & $23 \%$ & $3 \%$
\end{tabular} está desconectado da internet ou das redes sociais no seu Telefone Celular?

7. Com que frequência você sente nervosismo por não ter o Telefone Celular por perto para se comunicar?

8. Com que frequência você tem medo de sair sem o Telefone Celular e, se passar mal na rua, não ter como pedir "socorro" imediato ou fazer contato com alguém de sua confiança?

9. Com que frequência você mantém o Telefone Celular sempre $\quad 5 \% \quad \mathbf{4 9 \%} \quad \mathbf{4 6 \%}$ por perto mesmo em casa?

10. Com que frequência você mantém o Telefone Celular ligado $\quad 8 \% \quad 28 \% \quad \mathbf{6 4 \%}$ $24 \mathrm{~h}$ por dia?

11. Com que frequência você dorme com o Telefone Celular $\quad 11 \% \quad 28 \% \quad \mathbf{6 1 \%}$ ligado?

12. Com que frequência você acessa o Telefone Celular mais de $\quad \begin{array}{llll}16 \% & \mathbf{4 1 \%} & \mathbf{4 3 \%}\end{array}$ 30 vezes por dia para ver mensagens, e-mails etc.?

$\begin{array}{llll}\text { 13. Com que frequência você não se desliga do Telefone Celular } \quad 33 \% & 49 \% & 18 \%\end{array}$ quando está com amigos ou família?

$\begin{array}{llll}\text { 14. Com que frequência você sente solidão quando não participa } \quad \mathbf{8 5 \%} & 11 \% & 3 \%\end{array}$ de redes sociais ou quando não está inserido em grupos que os outros estão?

15. Com que frequência você insere na agenda do Telefone $\mathbf{8 7 \%} \quad 10 \% \quad 3 \%$

Celular o número de um médico, psicólogo ou hospital com medo de passar mal na rua?

\begin{tabular}{llll}
\hline 16. Com que frequência você joga no Telefone Celular? & $\mathbf{8 0 \%}$ & $13 \%$ & $7 \%$ \\
\hline
\end{tabular}

Fonte: dados da pesquisa

O resultado da escala demonstra que a maioria dos participantes apresenta algum tipo de relação de dependência do celular, sendo $8 \%$ numa relação grave, $57 \%$ moderada e $33 \%$ leve. Apenas $2 \%$ apresentaram uma relação de normalidade no uso do celular (Figura 1).

Figura 1 - Gráfico geral de dependência do celular

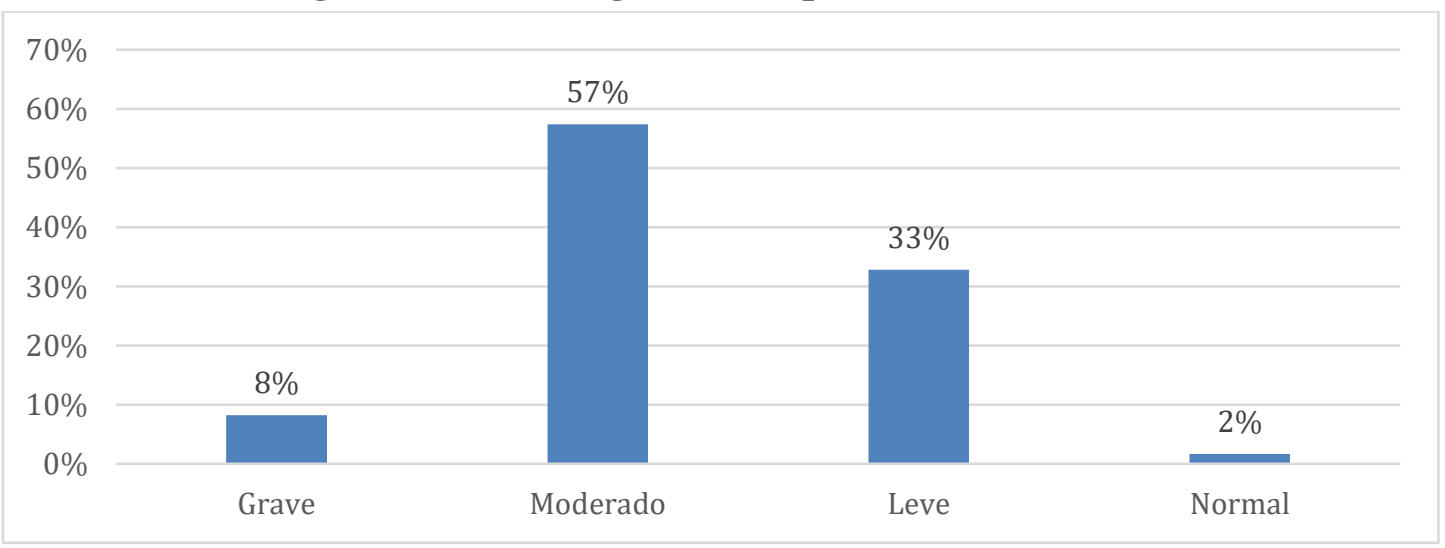

Fonte: dados da pesquisa. 
Quase a totalidade dos participantes, 86\%, trabalham. Dessa forma, além das atividades pessoais e profissionais, as acadêmicas passaram a ser mais acessadas através do celular. Os discentes do doutorado apresentaram um resultado de $4 \%$ para grave, $62 \%$ para moderado e $35 \%$ para leve; já no que diz respeito aos do mestrado, $5 \%$ tiveram resultado considerado normal, 33\% leve, $52 \%$ moderado e $10 \%$ grave. Entre os docentes, $9 \%$ obtiveram resultado grave, $55 \%$ moderado e $36 \%$ leve.

A categoria dos Técnicos Administrativos foi a que apresentou maior concentração no resultado de dependência, sendo $67 \%$ moderado e $33 \%$ grave. Nessa categoria profissional, não houve resultados classificados como leves ou normais pela escala.

\section{Figura 2 - Distribuição de participantes por tipo de relação com o Programa de Pós-graduação}

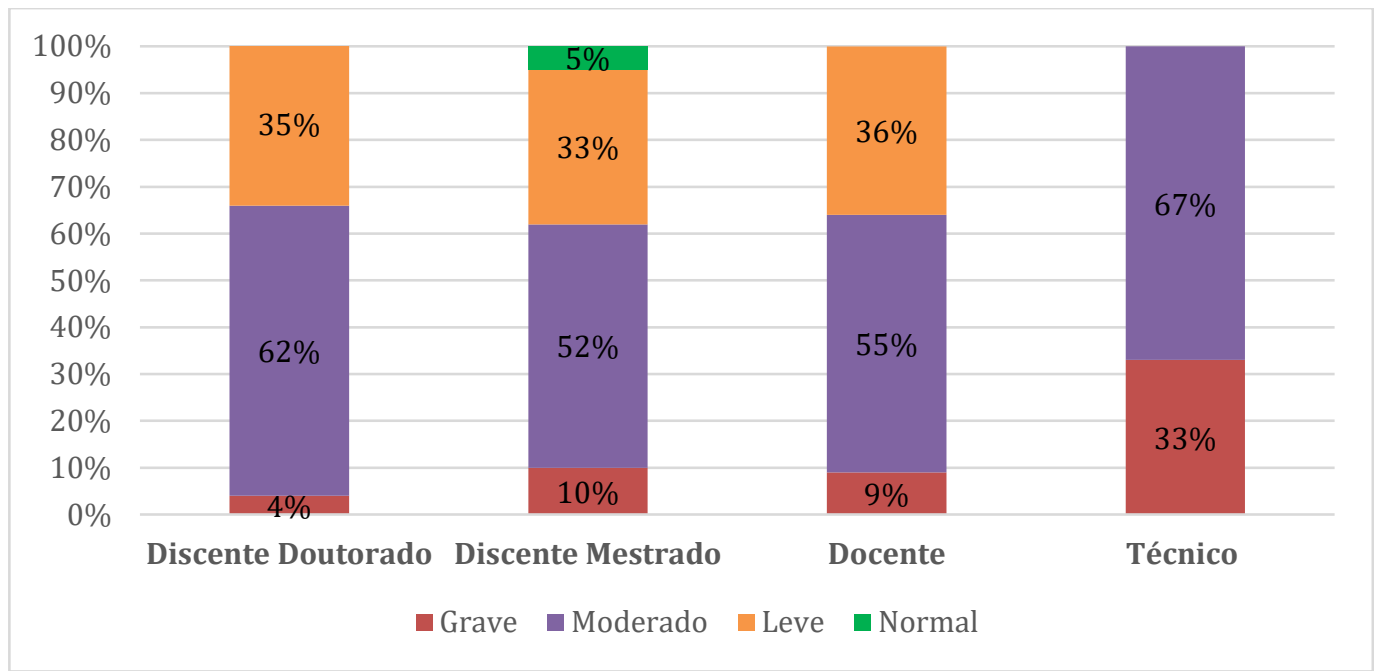

Fonte: dados da pesquisa.

\section{Discussão}

No cotidiano dos participantes, a presença ou indisponibilidade do smartphone, em maior ou menor grau, aponta para algum tipo de dependência. 98\% afirmaram que usam o celular no dia a dia (frequentemente ou sempre) e $97 \%$ acessam a internet pelo aparelho. Se unirmos as duas condições, veremos que $96 \%$ dos participantes que estão frequentemente ou sempre com o celular no dia a dia também acessam a internet pelo dispositivo.

Esse uso resulta numa necessidade de sempre estar com o aparelho, o que leva $64 \%$ (34\% frequentemente e $30 \%$ sempre) dos participantes a retornarem para buscá-lo quando o esquecem. Isso se dá especialmente pelo fato de que o celular, que anteriormente tinha como diferencial apenas a mobilidade, passou a oferecer diversos recursos, como "visualização de fotos, vídeos, câmera, acesso à internet, conexão com outros aparelhos, entre muitos outros recursos" (KING, 2019, p. 1) que estão vinculados ao cotidiano dos seus usuários. Assim, estando imerso no cotidiano, o acesso contínuo à internet ou a outros aplicativos utilizados consolida o celular como um portal pessoal (DE OLIVEIRA; PASQUALINI, 2014).

Os participantes não possuem o hábito de jogar pelo celular, o que pode estar relacionado, especialmente, à idade ou ao fato de trabalharem, uma vez que $80 \%$ declararam que nunca ou raramente jogam. 
Sobre reflexos no comportamento, a maioria alega não se sentir triste ou depressiva por estar desconectada (74\%), nem mesmo algum tipo de nervosismo (72\%). Além disso, esses participantes apontam não sentir solidão quando não participam de redes sociais ou quando não estão inseridos em grupos que os outros estão (85\%), e não inserem na agenda do telefone celular o número de um médico, psicólogo ou hospital com medo de passarem mal na rua (87\%).

Quanto ao fato de respostas indicarem uma relação normal de uso do dispositivo, é preciso salientar que a percepção da dependência digital não começa com grandes episódios na vida do indivíduo. Ela pode ser percebida em fenômenos específicos como vibração fantasma e eu estendido, hábitos ou episódios por vezes ignorados pelos usuários (DE OLIVEIRA; PASQUALINI, 2014; OLIVEIRA et al., 2020).

Além disso, o mesmo público que aponta para um uso normal do dispositivo, em sua maioria, frequentemente ou sempre retorna para casa para buscar o aparelho quando o esquece (34\% e $30 \%$, respectivamente). Também frequentemente $(31 \%)$ ou sempre (13\%) sente ansiedade quando percebe que está sem o aparelho.

A idade, aparentemente, não foi um fator muito significativo no resultado, visto que o público se tratava de pessoas adultas e com pouca discrepância na faixa etária. Vale ressaltar, no entanto, que o vício em smartphones é prevalente e ocorre com mais frequência entre os adultos mais jovens, mostrando que aqueles que exibiam vício em smartphones tiveram um sono mais pobre (SOHN, 2021, p. 9).

A categoria docente segue a tendência da categoria discente no espectro do resultado, apesar de não ser possível associar a relação com o celular à ação pedagógica. No entanto, já há trabalhos que relacionam problemas no ambiente universitário com a nomofobia, com reflexos na aprendizagem e na atuação docente (RABELO et al., 2020; NUÑEZ, 2020).

Os participantes revelaram que sempre mantêm o celular próximo de si, mesmo estando em casa, e ainda que checam o aparelho mais de 30 vezes por dia para ver mensagens, e-mails etc. Se, por um lado, isso pode ser considerado uma praticidade contemporânea; por outro, pode acarretar sérias implicações sociais e laborais. Tendo em vista a dificuldade de se reconhecer a dependência digital, a linha que separa o uso do vício em celular é tênue. Seja na universidade, no trabalho ou em casa, o celular ocupa cada vez mais espaço na rotina dos usuários. Dessa forma, definir se um uso é abusivo ou considerado normal ainda é um desafio que exige uma análise complexa (OLIVIERA et al., 2020).

\section{Conclusões}

A observação de uma escala mais objetiva é importante para o delineamento de um cenário de movimento, mesmo não sendo suficiente para a realização de um diagnóstico. O resultado da aplicação da escala de dependência do celular na comunidade acadêmica estudada demonstrou que os participantes podem já possuir algum tipo de dependência do uso de celular, sendo a categoria dos técnicos-administrativos a de maior incidência de casos graves e moderados.

Discentes e docentes possuem uma relação de dependência similar, com destaque aos discentes de mestrado. Isso por eles serem os únicos a apresentar uma relação, mesmo que pequena, de normalidade.

A dependência digital será um desafio para a sociedade hiperconectada, uma vez que essas formas de contato e seus dispositivos estão relacionados diretamente com as características desse novo paradigma da condição humana. 
Ainda não é seguro inferir uma relação de causalidade entre a exposição tecnológica na pandemia e a dependência do uso de celular, uma vez que esses dispositivos já faziam parte do cotidiano dos participantes, antes da pandemia. O estudo apresenta um cenário específico e não pode ser generalizado, já que o universo pesquisado, apesar de diverso, foi pequeno.

Apesar de não haver uma constatação de relação grave de dependência do smartphone, é preciso assumir o risco do viés de resposta por parte dos participantes, exigindo novas pesquisas, com estratégias que possam reduzir esses riscos. Trabalhos futuros, nesse sentido, poderão associar a aplicação do teste a entrevistas ou mesmo observação de campo por parte do pesquisador, qualificando os resultados coletados quantitativamente.

\section{Referências}

ANATEL - Agência Nacional de Telecomunicações. Relatório de acompanhamento do setor de telecomunicações Telefonia Móvel. $2^{\circ}$ semestre de 2020. Disponível em: <https://bit.ly/3oRF6Gj>. Acesso em: 10 jul. 2021.

APP ANNIE State of mobile 2021. App Annie. Disponível em:

<https://bit.ly/3FHOeDz>. Acesso em: 10 jul. 2021.

BHATTACHARYA, Sudip et al. Nomophobia: No mobile phone phobia. Journal of family medicine and primary care, v. 8, n. 4, p. 1297, 2019.

BORGES, Luana de Andrade Pinheiro; PIGNATARO, Thelma. Nomofobia: uma síndrome no séc. XXI. Revista INTERFACE-UFRN/CCSA ISSN 2237-7506, v. 13, n. $1,2016$.

BRASIL. Ministro de Estado da Educação. Gabinete do Ministro. Portaria n. ${ }^{0}$ 343, de 17 de março de 2020. Brasília, 2020.

CHÓLIZ, Mariano. Mobile-phone addiction in adolescence: the test of mobile phone dependence (TMD). Progress in health sciences, v. 2, n. 1, p. 33-44, 2012.

DE ABREU, Cristiano Nabuco; EISENSTEIN, Evelyn; ESTEFENON, Susana Graciela Bruno. Vivendo esse mundo digital: impactos na saúde, na educação e nos comportamentos sociais. Artmed Editora, 2013.

DE ANDRADE CARNEIRO, Leonardo et al. Uso de tecnologias no ensino superior público brasileiro em tempos de pandemia COVID-19. Research, Society and Development, v. 9, n. 8, p. e267985485-e267985485, 2020.

DE OLIVEIRA, Fabrícia; PASQUALINI, Kele Cristina. Os dependentes de internet no Brasil: realidade ou mito entre os universitários. 2014.

FREITAS, Marinaide et al. O "vírus" da exclusão socioeconômico-digital no ensino superior em tempos de COVID-19. Educação, Sociedade e Culturas, n. 59, 2021.

GIL, Antônio Carlos et al. Como elaborar projetos de pesquisa. São Paulo: Atlas, 2002.

KING, Anna Lucia Spear et al. Validation of the Cell Phone Dependence Scale. MedicalExpress, v. 6, 2019.

KWON, Min et al. Development and validation of a smartphone addiction scale (SAS). PloS one, v. 8, n. 2, p. e56936, 2013.

LIN, Yu-Hsuan et al. Development and validation of the Smartphone Addiction Inventory (SPAI). PloS one, v. 9, n. 6, p. e98312, 2014. 
MAZIERO, Mari Bela; OLIVEIRA, L. A. Nomofobia: uma revisão bibliográfica. Unoesc \& Ciência-ACBS, v. 8, n. 1, p. 73-80, 2016.

MÉLO, Cláudia Batista et al. Ensino remoto nas universidades federais do Brasil: desafios e adaptações da educação durante a pandemia de COVID-19. Research, Society and Development, v. 9, n. 11, p. e4049119866-e4049119866, 2020.

MORILLA, J. L.; VIEIRA, G. C.; DANTAS, C. N.; CASSAGO, R. M.; PUCCI, S. H. M.; GOBBI, D. R. Nomofobia: uma revisão integrativa sobre o transtorno da modernidade. Revista de Saúde Coletiva da UEFS, [S. l.], v. 10, n. 1, p. 116-126, 2020. DOI: 10.13102/rscdauefs. v10i1.6153. Disponível em: <http://periodicos.uefs.br/index.php/saudecoletiva/article/view/6153>. Acesso em: 10 jan. 2021.

NÚÑEZ, Juan Antonio López et al. Nomofobia: análisis de su prevalencia en futuros docentes. In: La tecnología como eje del cambio metodológico. UMA Editorial, 2020. p. 863-866.

OLIVEIRA, M. Vítimas da dependência digital. Revista Isto é. Ed. 2289 Editora 3, 2013. Disponível em: <https://bit.ly/3boCiIO>. Último acesso em: 10 jul. 2021.

OLIVEIRA, Thyciane Santos et al. Tenho celular, logo existo: um estudo da nomofobia na formação de futuros gestores. Revista de Administração Unimep, v. 18, n. 1, p. 91$110,2020$.

PINHEIRO, Ana Paula; PINHEIRO, Fernanda. O uso do celular em tempos de pandemiauma análise da nomofobia entre os jovens. Revista Tecnologias Educacionais em Rede (ReTER), v. 2, n. 3, p. 9-01-15, 2021.

PISSAIA, Luís Felipe; DA COSTA, Arlete Eli Kunz. Pandemia da covid-19: percepções de estudantes de enfermagem sobre o seu ensino. Oikos: Família e Sociedade em Debate, v. 32, n. 1, p. 148-164, 2021.

RABELO, Leonardo Moreira; ALEXANDRE, Krislayne Veras; DE MOURA RODRIGUES, Gabriela Meira. Nomofobia, uso de telefone e redes sociais prejudica o aprendizado de estudantes universitários? Revista Liberum accessum, v. 3, n. 1, p. 1-7, 2020.

SEVERINO, Antônio Joaquim. Metodologia do trabalho científico. Cortez Editora, 2017.

SOHN, Sei Yon et al. The association between smartphone addiction and sleep: a UK cross-sectional study of young adults. Frontiers in psychiatry, v. 12, 2021. 